\title{
Fungal communities in Macaca fascicularis and Macaca nemestrina associates with forest matrix types in West Malaysia
}

\begin{abstract}
Genetic and geographical proximity between Macaca fascicularis, Macaca namestrina and humans are posing a dangerous threat in terms of disease transmission to humans. The objective is to determine the fungal species in actively shedding anatomical sites of these macaques inhabiting forest fragment of different matrix types in Kemasul Forest Reserve, Pahang State, Malaysia. Matrix of Chemomoi (CM) had higher coverage of acacia (Acacia mangium), whereas JambuRias (JR) encompassed oil palm plantation. Swab samples were obtained from throat, anus and penis/vagina of three individual of macaques from each species and geographic location $(\mathrm{N}=12)$. The swabs were then streaked onto Potato Dextrose Agar plate containing $25 \mathrm{mg} / \mathrm{ml}$ chloramphenicol to obtain pure colony. The isolated fungal species were identified morphologically, and molecular identification was carried out in some of the isolates. The results reveal 18 fungal species from 10 genera identified, with JR showing 13 species compared to CM with only 7 species, but significant difference was observed between fungal distribution in different geographical locations and macaques species $(p<0.05)$. Fungal species from both macaque species were higher in JR compared to $\mathrm{CM}$ but no significant difference in different anatomical sites.The most common fungi species found in JR is Aspergillus fumigatus, as it was found in all anatomical sites of both macaques but it was absent from samples in CM. Only two fungi species shared between both geographic locations which are A. ruber and A. flavus. This study reveals potential risk to both human-macaque, thus relocating the human settlements adjacent to the forests and proper waste management system are essential.
\end{abstract}

Keywords: actively shedding fungi, macaques, forest plantations, Malaysia
Volume 8 Issue I - 2020

\author{
Farah Shafawati Mohd-Taib,' Siti Najwa \\ Ahmad,' Wan Syaidatul Aqma,' Frankie \\ Thomas Sitam ${ }^{2}$ \\ 'Department of Biological Sciences and Biotechnology, Faculty \\ of Science and Technology, Universiti Kebangsaan Malaysia, \\ Malaysia \\ ${ }^{2}$ Department of Wildlife and National Park Peninsular, Malaysia
}

Correspondence: Farah Shafawati Mohd-Taib, Department of Biological Sciences and Biotechnology, Faculty of Science and Technology, Universiti Kebangsaan Malaysia, Malaysia, 43600 UKM Bangi Selangor, Malaysia, Email farah_s@ukm.edu.my

Received: December 23, 2019 | Published: January 10, 2020

\section{Introduction}

Increasing human population has resulted in a higher number of human intrusion in wildlife habitat, leading to human-primates (NHPs) conflicts. ${ }^{1}$ Twigg ${ }^{1}$ also stated that pest behavior among NHPs have been observed in urban environment as they raid trash for food. Dumping of rubbish from human food near their habitat is also one of the reason for increased human-primate infringement. ${ }^{2}$

The declining habitats force macaques to migrate near human settlements. Due to the lack of food source from the forest caused by deforestation, macaques quickly learn to raid crops or garden from agriculture land. These raid incidents increase the chances of human-macaque interactions that can lead to other incidents. Macaca fascicularis and M. namestrina are susceptible to different dangerous biological agents that are transmittable to human due to the close proximity in genetics and geography. According to Pederson \& Davies, ${ }^{2}$ cross species disease transmission is caused by three major factors and one of them is overlapping geographical distribution. Besides that, biological factors such as genetic similarity highly determine a successful transmission and infection. ${ }^{3}$ Close genetic relationships among host species might translate into similar immunological responses. ${ }^{3}$ As a consequence macaques living in such close distance with humans, are serving as a main source of disease transmission. While $M$. fascicularis is not currently a species of concern on the International Union for Conservation of Nature (IUCN) list, whereas M. nemestrina is considered 'Vulnerable'. ${ }^{4}$

Current knowledge of fungal diseases in macaques in relation to habitat disturbance is somewhat patchy, as many studies focus on specific case study. The closest study by Carvalho et al., 5 on nasal, oral and rectal of black lion tamarins (Leontopithecus chrysopygus) found that mycelium fungi were the most frequently found fungal species from nasal and oral area while yeast fungus were found from anal samples. Mycelium fungi isolated include Aspergillus, Candida, Penicillium and Trichoderma. Aspergillus conidia can be easily inhaled into the human lungs causing various diseases such as invasive pulmonary aspergillosis, aspergilloma, and can lead to hypersensitivity diseases including allergic asthma, hypersensitivity pneumonitis, and allergic broncho pulmonary aspergillosis. ${ }^{6}$ Frequent interaction between humans and macaques can increase the risk of fungal spores' transmission. Besides fungal infection diseases, humans are also at risk of toxin produced by Aspergillus genus known as mycotoxin and aflatoxin. ${ }^{?}$

Humans who feed and interact with the macaques can either be exposed to zoonotic diseases after being bitten or scratched such as simian foamy virus. ${ }^{8}$ According to Jones et al, ${ }^{8}$ there is potential for previously unknown diseases transferred from the monkeys to humans who were feeding them, posing a serious health risk to the surrounding communities. ${ }^{8}$

Chikungunya Virus (CHIKV) has caused epidemics worldwide of rash, fever and althralgia in the last decade. ${ }^{9}$ Recent studies have revealed the presence of this virus in macaques in Malaysia, especially in Perak and Kuala Lumpur. ${ }^{10}$ In Northern Thailand, a number of viruses were found among $M$. namestrina. ${ }^{11}$ The viruses include Dengue virus, Japanese Encephalitis and Chikugunya virus making M. namestrina a very harmful virus reservoir to human as they live in close proximity. 
According to Demanche et al., ${ }^{12}$ Pneumocystis carinii is one of the most regular fungal pathogen infecting primates. They also stated that the same agent can cause Pneumocystis carinii pneumonia (PCP), which is one of the most critical fungal respiratory infections that can develop in immune compromised patients. A case report was written regarding an infection of Coccidioides spp. resulting in disseminated coccidioidomycosis that was later identified to be the cause of impaired locomotion ability in a 5-year, 10-month-old male M. fascicularis. ${ }^{13}$ Symptoms found in the infected macaque include Pyogranulomatous inflammation and spherules in the tissue. Coccidioides spp. is a pathogenic fungus usually found in the soil of some region in United States, Central and South America and also Mexico. This fungal species naturally infectes wild rodents and they can be isolated in high concentration from the rodents' habitat. ${ }^{13}$ Coccidioides spp. will grow into vegetative state after some periods of rain, and dispersed under dry and windy conditions. ${ }^{14}$

We want to determine the fungal species distribution in different anatomical sites of macaques, in relation to habitat condition. The macaques have been reported encroaching near human settlements in Kemasul Forest Reserve, Pahang. The surrounding forest area was demolished and substituted with acacia, oil palm and rubber plantation. Chemomoi (CM) and Jambu Rias (JR) was an extended forest fragment, with different surrounding matrix types. CM were surrounded by Acacia plantation (Acacia mangium), which is a rapidly growing plant species, whereas JR were surrounded with oil palm plantation. Oil palm plantations were known as disturbed habitat due to the manipulation of natural forest with the use of pesticides, human interference and invasion of foreign species, making it a incongruous habitat for wildlife. We hypothesize forest with oil palm matrix would yield a higher fungal infection due to its more disturbed nature as more fungal spores were produce from the soil and the plant itself. M. facicularis is more adapted and lives close to human settlements, therefore we anticipate that this species exhibit higher fungal distribution, compared to M. namestrina. We also expect different fungal isolates in different anatomical sites.

\section{Materials and methods}

\section{Study areas}

Kemasul Forest Reserve is located between three districts in Pahang State of Peninsular (West) Malaysia (Figure 1) which are Bera, Temerloh and Bentong. Intense deforestation for commercial plantations has taken place in the forest reserve, leaving forest fragments scattered in the landscape. Two geographic locations within Kemasul Forest Reserve (FR) were chosen for sampling were JambuRias (JR) and Chemomoi (CM) as shown in Figure 2. Both locations differ in matrix types, where JR is surrounded by mixture of oil palm and rubber plantation, whereas CM is surrounded by acacia plantation (Acacia mangium).

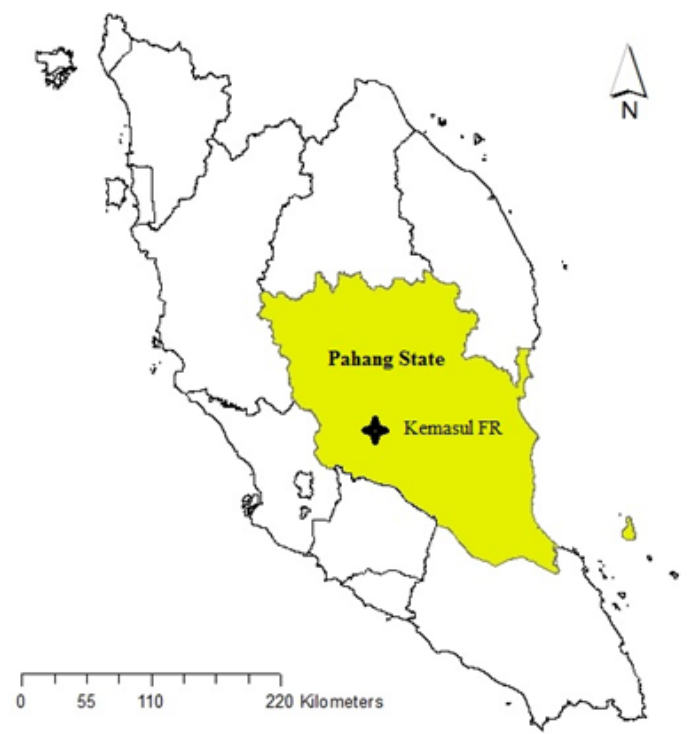

Figure I Location of Kemasul FR in Pahang State in Peninsular Malaysia.

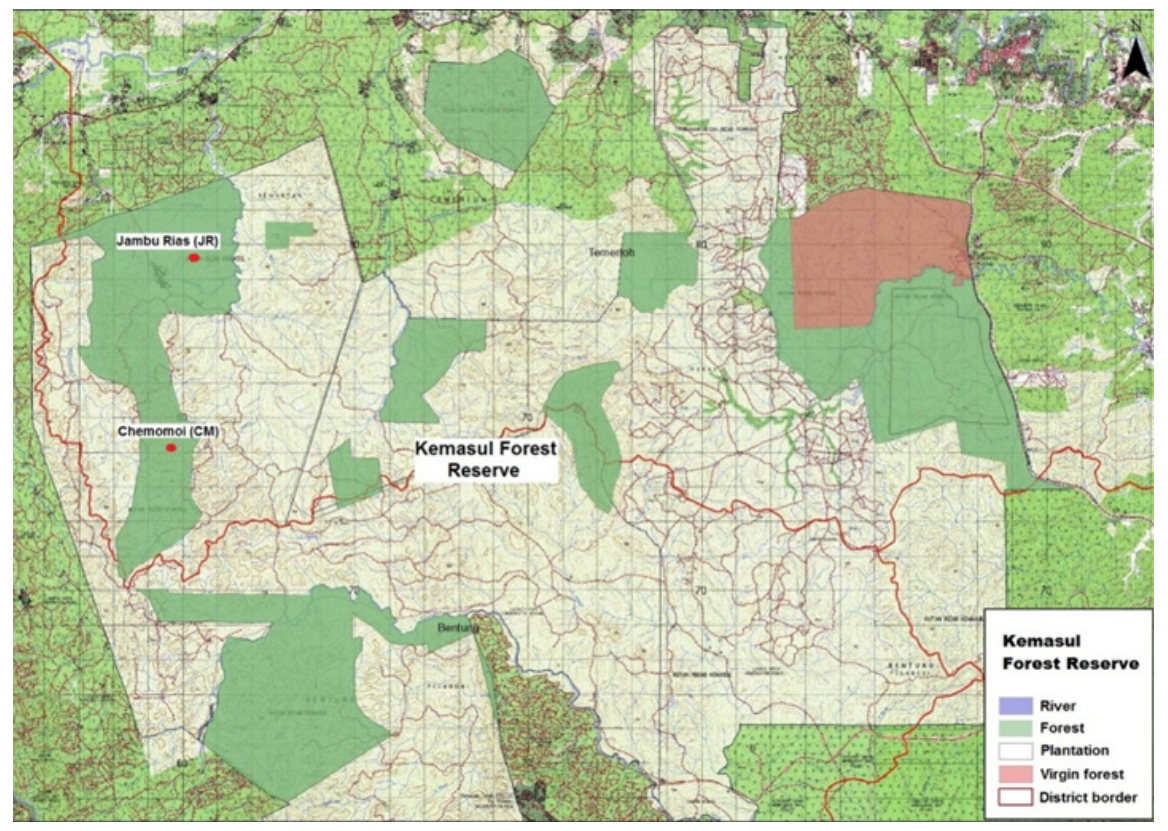

Figure 2 Jambu Rias (JR) and Chemomoi (CM) in Kemasul Forest Reserve, Pahang. 


\section{Sampling of macaques}

Capture-release method for M. fascicularis and M. namestrina was employed in this study between August and November 2015 at both JR and CM. Macaques were captured using 30 large wire mesh live cage traps $(38 \times 38 \times 106) \mathrm{cm}$. Traps were deployed in 6 transect lines of $50 \mathrm{~m}$ length which located at different location in the forest. Jackfruit was used as bait due to its strong aromatic smell. The captured macaques were then anesthetized using 2-3ml of Zoletil to collect the samples. Sterile swabs were used to collect samples in three anatomical sites: anus, throat and penile-vaginal. The swabs were then stored in a tube containing lysis buffer for preservation and kept within liquid nitrogen before being transported back to the Environmental Microbiology Laboratory in UniversitiKebangsaan Malaysia (UKM), Bangi. List of individuals captured is listed in Table 1.

Table I Samples from individuals captured according to geographic location, sex and age

\begin{tabular}{|c|c|c|c|c|}
\hline Site & Species & ID & Sex & Age \\
\hline \multirow{6}{*}{$J R$} & & WRG 0008 & $\mathrm{~F}$ & A \\
\hline & M. fascicularis & WRG 0009 & $\mathrm{~F}$ & A \\
\hline & & WRG 0013 & M & A \\
\hline & & WRG 0001 & $M$ & $A$ \\
\hline & M. nemestrina & WRG 0002 & $M$ & $A$ \\
\hline & & WRG 0006 & $\mathrm{~F}$ & SA \\
\hline \multirow{6}{*}{$C M$} & & WRG 0016 & $\mathrm{~F}$ & $J$ \\
\hline & M. fascicularis & WRG 0018 & $M$ & A \\
\hline & & WRG 0027 & $\mathrm{~F}$ & SA \\
\hline & & WRG 0017 & $\mathrm{~F}$ & A \\
\hline & M. nemestrina & WRG 0028 & $M$ & A \\
\hline & & WRG 0030 & $\mathrm{~F}$ & A \\
\hline
\end{tabular}

(Sex: $M=$ male, $F=$ female;Age: $A=$ adult, $S A=$ sub-adult, $J=$ juvenile)

\section{Ethical note}

All procedures were approved by UKM Animal Ethic Committee with approval number FST/2016/SHUKOR/18-MAY/750-MAY2016-SEPT.-2018-AR-CATS. All captured individuals were released at the point of capture after they gained conciousness.

\section{Determination of fungal species}

Three individuals were chosen for $M$. fascicularis and $M$. namestrina sampled at both study areas $(\mathrm{N}=12)$. Swabs from all three anatomical sites of each individual were streaked on Potato Dextrose (PDA) agars infused with Chloramphenicol $25 \mathrm{mg} / \mathrm{mL}$ then poured onto $9 \mathrm{~cm}$ petri dish, before incubation at $30^{\circ} \mathrm{C}$ under both aerobic and anaerobic condition for 30 days. Sub-cultured fungal isolates were incubated for 14 days or until full sporulation. Control plates were incubated along with the swabbed plates to ensure aseptic condition with no fungal contamination from media/air/incubators. Lactophenol cotton blue staining method was used for morphological identification of fungal species under light microscope at $100 \times$ magnification. Identifications of fungal species were based on Howard ${ }^{15}$ and StGermain \& Summerbell. ${ }^{16}$ For presumed Basidiomycete isolates, molecular identification was carried out due to inadequate sporulation. The DNA of fungal isolates were extracted and the fragments of ITS region of rRNA gene was amplified by PCR before sequencing followed by fungal barcoding protocol according to Raja et al. ${ }^{17}$ Results from the nucleotide sequences were compared with the reference sequences available in National Centre for Biotechnology Information (NCBI) database using the Basic Local Alignment Search Tool (BLAST) algorithm.

\section{Data analysis}

Mean and standard error of number of species isolated from different anatomical sites were calculated for each geographic location, according to macaques' species. Normality test performed showed a non-normal distribution between number of fungal species and each variables (Shapiro-Wilk $\mathrm{p}<0.05$ ), therefore, we used non-parametric test. Mann-Whitney U test was used to determine the differences in number of fungi species between the two macaques species, as well as between two geographical locations. Kruskal-Wallis $\mathrm{H}$ test was used to determine the differences in number of fungal species between different anatomical sites.

\section{Results}

\section{Determination of fungal species}

A total of 18 species of fungal including both yeast and mycelium fungi were identified from all individuals of $M$. fascicularis and $M$. namestrina from $\mathrm{JR}(\mathrm{N}=6)$ and $\mathrm{CM}(\mathrm{N}=6)$ areas. All 18 isolates were identified under genera Aspergillus (6 species), Penicillium (3 species), Paecilomyces (2 species), Sporothrix (1 species), Geotrichum (1 species), Curvularia (1 species), Candida (1 species), Phellinus , (1 species), Basidiomycota (1 species)and Phebia (1 species)as seen in Table 2 and Table 3. Figure 3(a-s) illustrate photos of each fungus isolates.

Table 2 Fungal species identified in Jambu Rias (JR)

\begin{tabular}{|c|c|c|c|c|c|c|}
\hline \multirow{2}{*}{$\begin{array}{l}\text { Macaca species } \\
\text { Fungi/ } \\
\text { Anatomical } \\
\text { sites }\end{array}$} & \multicolumn{3}{|c|}{ Macacafascicularis } & \multicolumn{3}{|c|}{ Macacanamestrina } \\
\hline & Anus & Throat & $\begin{array}{l}\text { penis/ } \\
\text { vagina }\end{array}$ & Anus & Throat & $\begin{array}{l}\text { penis/ } \\
\text { vagina }\end{array}$ \\
\hline Aspergillus clavatus & + & + & + & - & - & - \\
\hline Aspergillus niger & - & - & - & + & + & - \\
\hline $\begin{array}{l}\text { Aspergillus } \\
\text { fumigatus }\end{array}$ & + & + & + & + & + & + \\
\hline Aspergillus candidus & - & - & + & - & - & - \\
\hline Aspergillus ruber & + & - & - & - & - & - \\
\hline Aspergillus flavus & - & - & + & - & - & - \\
\hline Curvularia lunata & + & - & - & - & - & - \\
\hline Sporothrix schenckii & - & - & - & - & + & - \\
\hline Candida parapsilosis & - & - & - & - & - & + \\
\hline
\end{tabular}


Table continue

\begin{tabular}{lllllll}
\hline Macaca species & \multicolumn{2}{c}{ Macacafascicularis } & \multicolumn{3}{c}{ Macacanamestrina } \\
\hline $\begin{array}{l}\text { Fungil } \\
\begin{array}{l}\text { Anatomical } \\
\text { sites }\end{array}\end{array}$ & Anus & Throat & $\begin{array}{l}\text { penis/ } \\
\text { vagina }\end{array}$ & Anus & Throat & $\begin{array}{l}\text { penis/ } \\
\text { vagina }\end{array}$ \\
\hline $\begin{array}{l}\text { Penicillium jensenii } \\
\begin{array}{l}\text { Penicillium } \\
\text { frequentans }\end{array}\end{array}$ & - & - & - & - & + & - \\
$\begin{array}{l}\text { Phellinus sp. } \\
\text { Basidiomycota sp. }\end{array}$ & - & + & - & - & - & - \\
\hline
\end{tabular}

Table 3 Fungal species identified in Chemomoi (CM)

\begin{tabular}{|c|c|c|c|c|c|c|}
\hline \multirow{2}{*}{$\begin{array}{l}\text { Macaca } \\
\text { species } \\
\text { Fungi/ } \\
\text { Anatomical } \\
\text { sites }\end{array}$} & \multicolumn{3}{|c|}{ Macacafascicularis } & \multicolumn{3}{|c|}{ Macacanamestrina } \\
\hline & Anus & Throat & $\begin{array}{l}\text { penis/ } \\
\text { vagina }\end{array}$ & Anus & Throat & $\begin{array}{l}\text { penis/ } \\
\text { vagina }\end{array}$ \\
\hline Aspergillus ruber & - & - & - & - & - & + \\
\hline Aspergillus flavus & - & - & - & - & - & + \\
\hline $\begin{array}{l}\text { Paecilomyces } \\
\text { lilacinus }\end{array}$ & + & - & - & - & - & - \\
\hline $\begin{array}{l}\text { Paecilomyces } \\
\text { variotii }\end{array}$ & - & - & - & + & - & - \\
\hline $\begin{array}{l}\text { Geotrichum } \\
\text { candidum }\end{array}$ & - & - & - & + & - & - \\
\hline
\end{tabular}

\begin{tabular}{lllllll}
\hline $\begin{array}{l}\text { Macaca } \\
\text { species }\end{array}$ & Macacafascicularis & \multicolumn{3}{l}{ Macacanamestrina } \\
\hline $\begin{array}{l}\text { Fungi/ } \\
\begin{array}{l}\text { Anatomical } \\
\text { sites }\end{array}\end{array}$ & Anus & Throat & $\begin{array}{l}\text { penis/ } \\
\text { vagina }\end{array}$ & Anus & Throat & $\begin{array}{l}\text { penis/ } \\
\text { vagina }\end{array}$ \\
\hline $\begin{array}{l}\text { Penicillium } \\
\text { canescens }\end{array}$ & - & - & - & + & - & - \\
$\begin{array}{l}\text { Phlebia sp. } \\
\text { palp }\end{array}$ & + & - & - & - & - & - \\
\end{tabular}

\section{Comparisons of fungal species distribution in different macaques' species and geographical locations}

Figure 4 illustrates fungal species distribution in different geographic locations, in macaque species. Fungal species isolates from M. fascicularis and M. nemestrina was generally higher in JR $(\mathrm{N}=13)$, compared to $\mathrm{CM}(\mathrm{N}=7)$. However, Man-Whitney $\mathrm{U}$ test revealed no significant differences between number of fungal species and geographic locations $(U=1470, z=-1.262, p=0.207)$. Fungal distribution in $M$. nemestrina was equally high in both geographic locations, compared to $M$. fascicularis which was significantly higher in JR compared to CM. M. nemestrina on the other hand, shows significantly higher fungal species compared to $M$. fascicularis at $\mathrm{CM}$, but Man-Whitney $\mathrm{U}$ test revealed no significant differences between the number of fungal species $(U=1404, z=-0.437, p=$ 0.662 ) in both macaques species. Thus, this study reveal no significant differences in number of fungal species on macaques' species, as well as geographic locations, although JR shows slightly higher fungal distribution compared to CM.
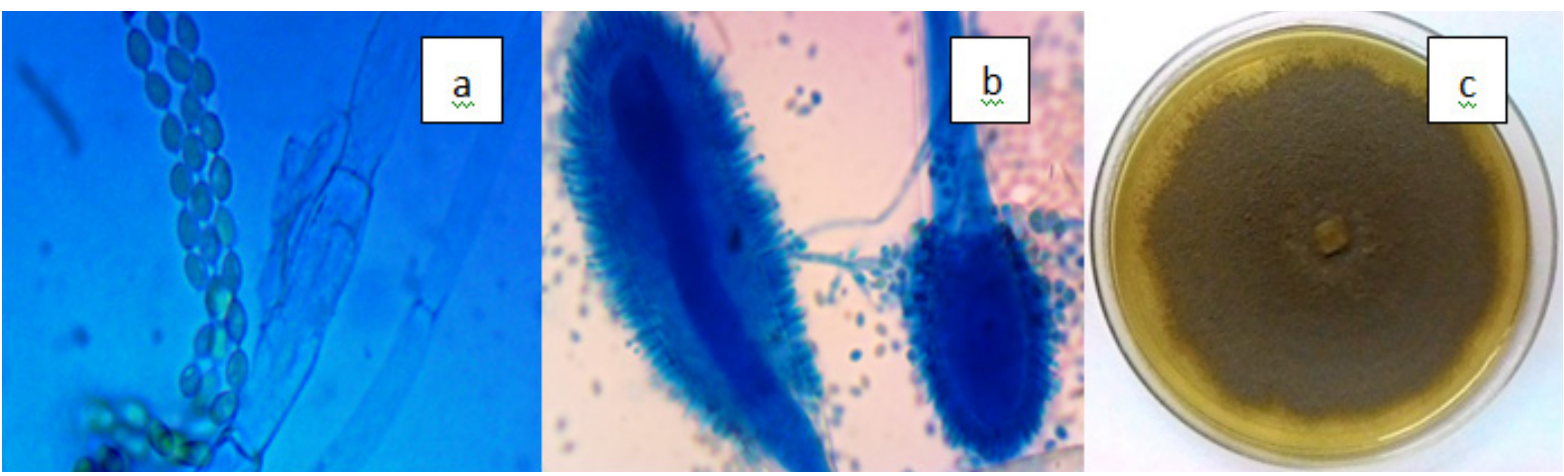

Figure 3(a) Aspegillus clavatus, a) clavate conidial head of A. clavatus, b) Septate hyphae and smooth-walled conidia (xI00), c) Greyish A. clavatus on PDA.

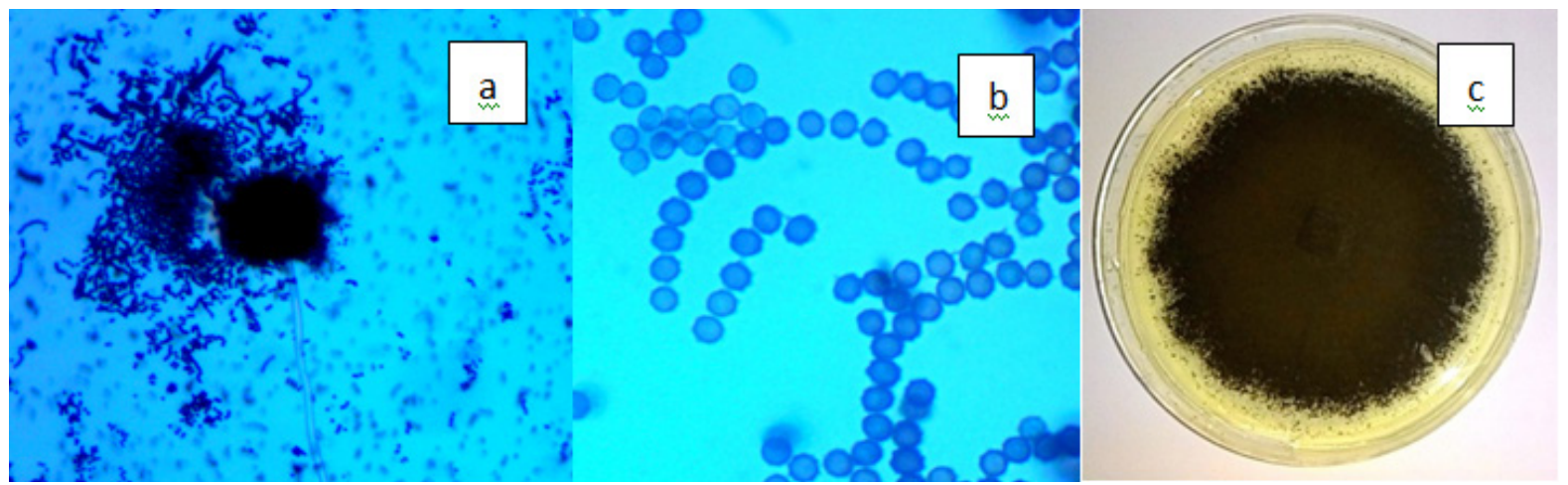

Figure 3(b) Aspergillus niger. a) Globose conidial head of A. niger, b) Rough-walled conidia (xI00), c) Powdery, black colony of A. niger on PDA. 


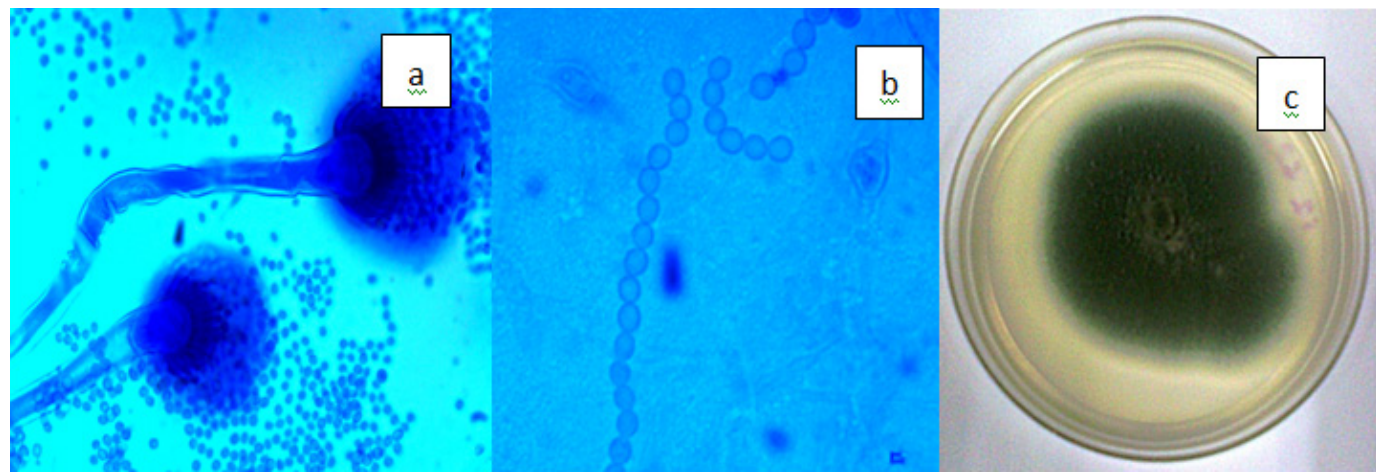

Figure 3(c) Aspergillus fumigatus. a) Conidial head of A. fumigatus, b) Smooth-walled conidia (x100), c) Thin, bluish green colony of $A$. fumigatus on PDA.

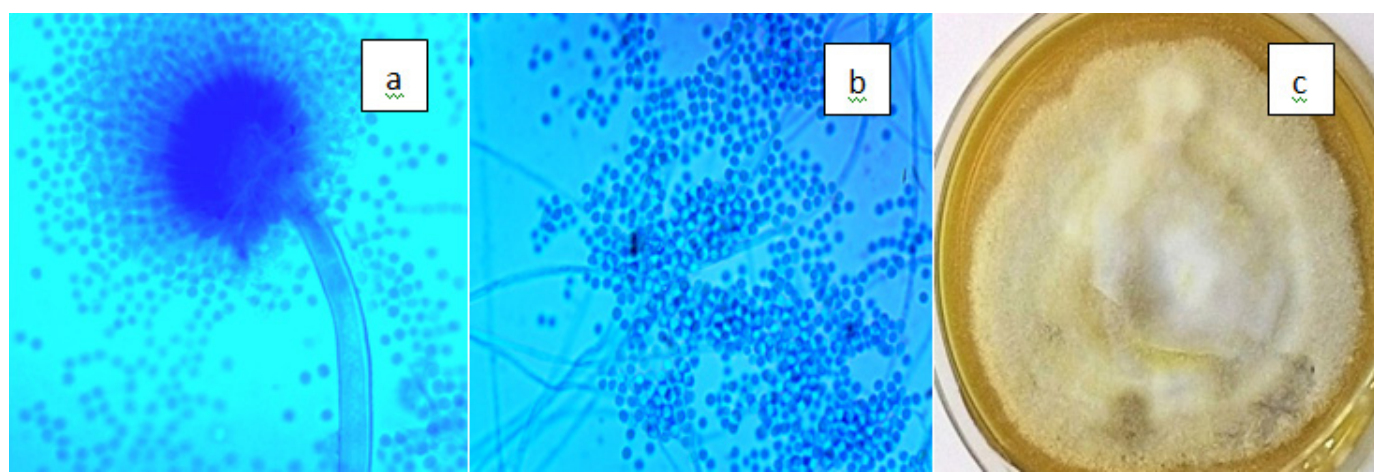

Figure 3(d) Aspergillus candidus. a) Globose conidial head of A. candidus, b) Smooth-walled conidia (x I00), c) Creamy white colony of A. candidus on PDA.
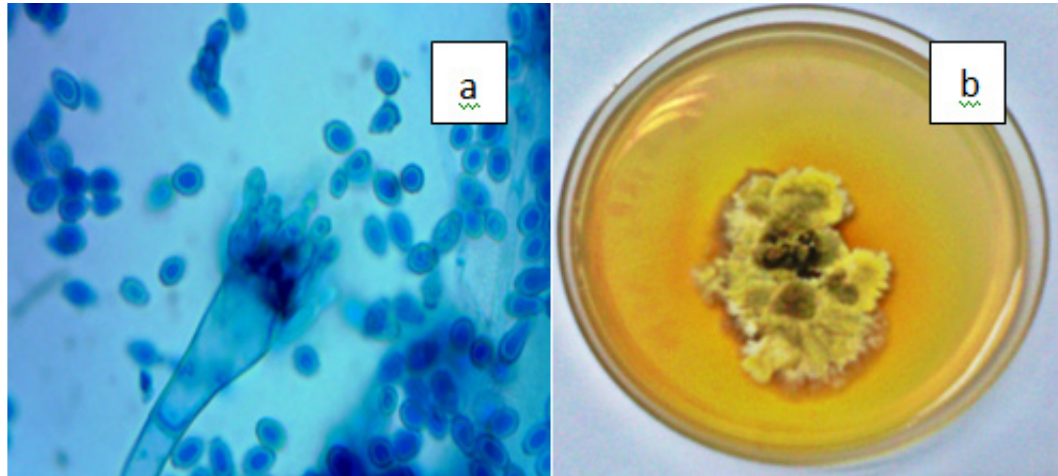

Figure 3(e) Aspergillus ruber. a) Conidial head of A. ruber (x100), b) Colony of A. ruber on PDA.

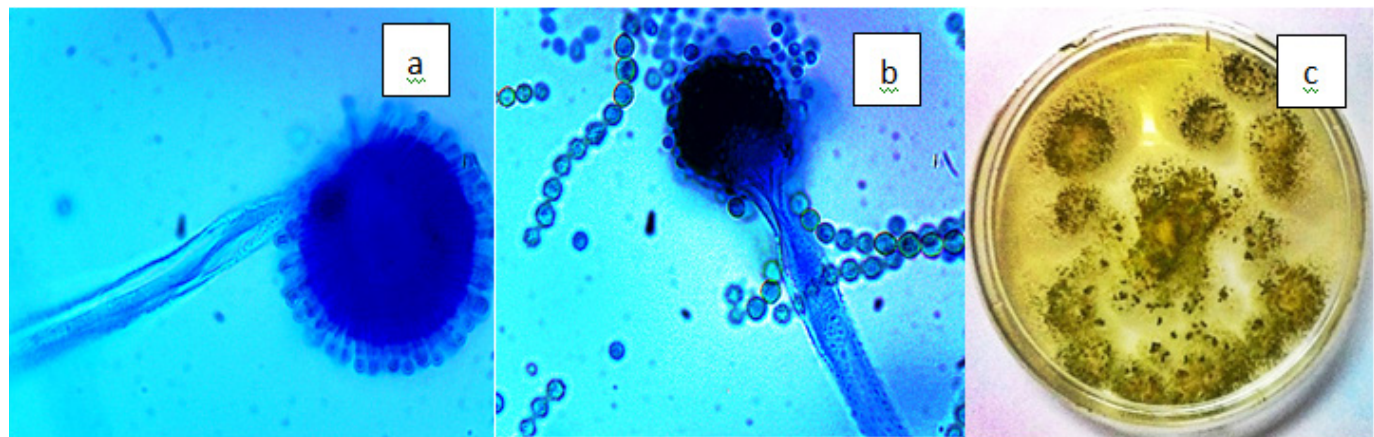

Figure 3(f) Aspergillus flavus. a) Radiating conidial head, b) Hyaline,rough walled conidiophore with conspicuously echinulate conidias (xI00), c) Yellow green colonies with dark brown sclerotia.

Citation: Mohd-Taib FS, Ahmad SN, Aqma WS, et al. Fungal communities in Macaca fascicularis and Macaca nemestrina associates with forest matrix types in West Malaysia.J Microbiol Exp. 2020;8(I):7-I8. DOI: 10.15406/jmen.2020.08.00279 

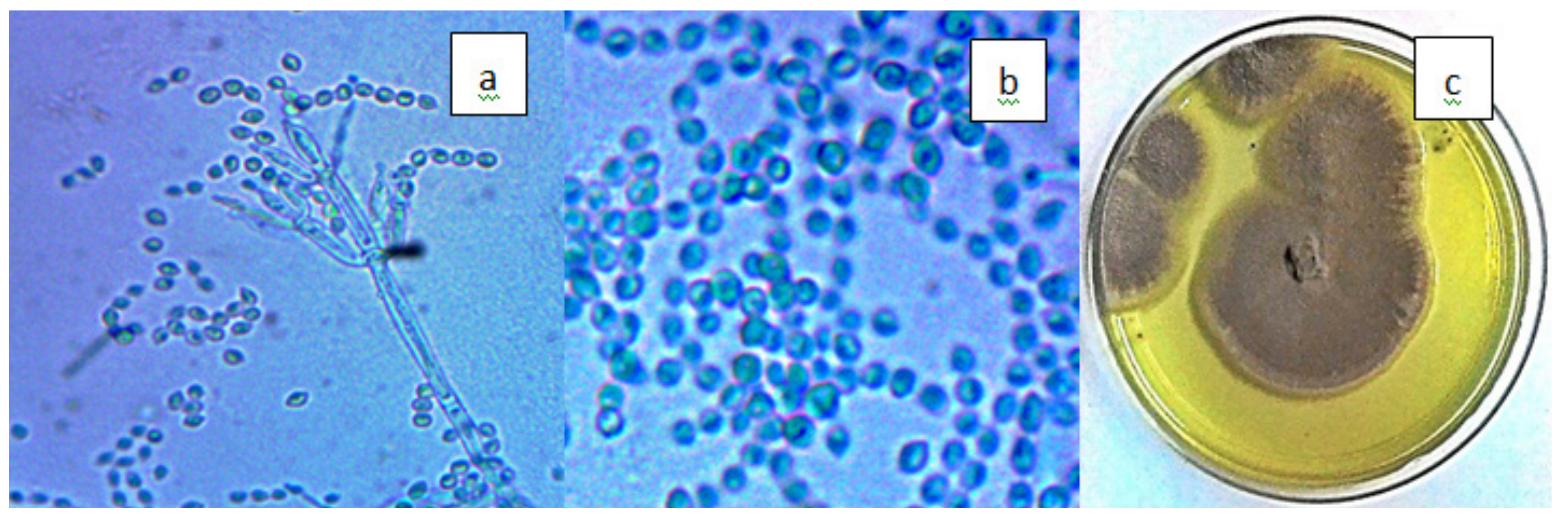

Figure 3(g) Paecilomyces lilacinus a) P. lilacinus phialides, b) Fusiform conidias (xI00), c) Vinaceous colonies on PDA.
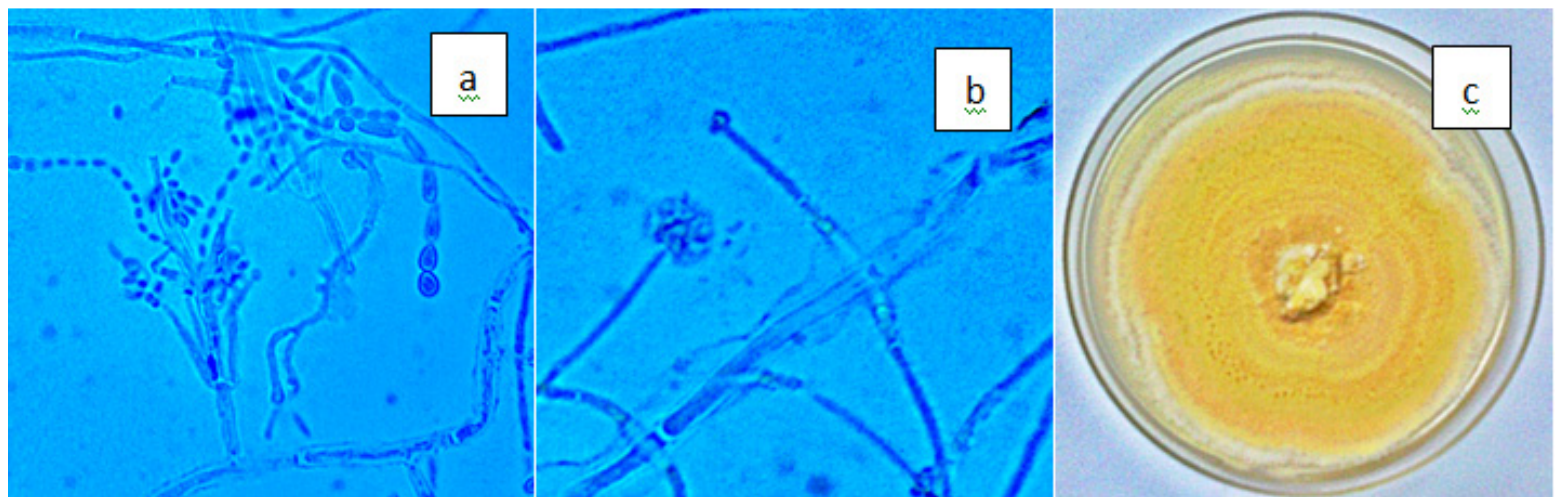

Figure 3(h) Paecilomyces variotii. a) P. variotii phialides and uneven sizes conidias, b) Chlamydospores of $P$. variotii (xI00), c) Olivaceous colonies on PDA.
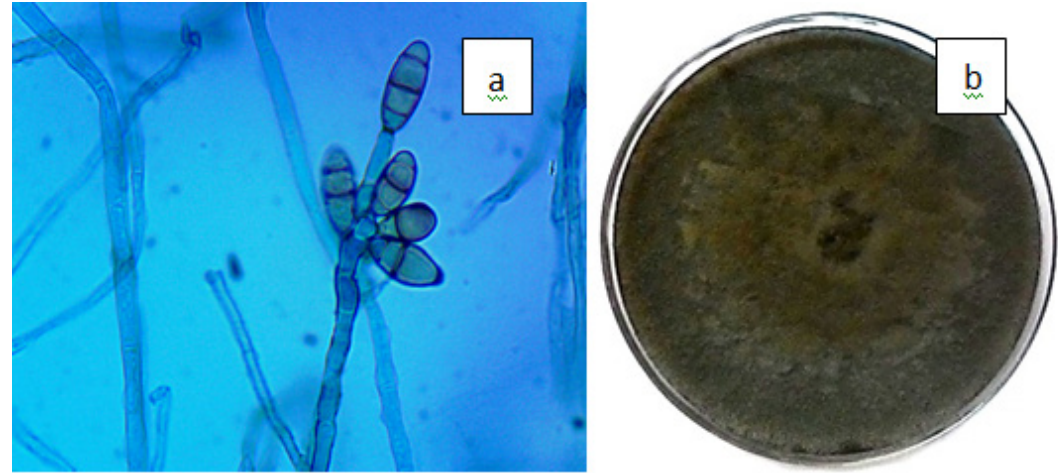

Figure 3(i) Curvularia lunata. a) Conidiophores and conidia of C. lunata (xI00), b) Dark brown, velvety C. lunata colony on PDA.
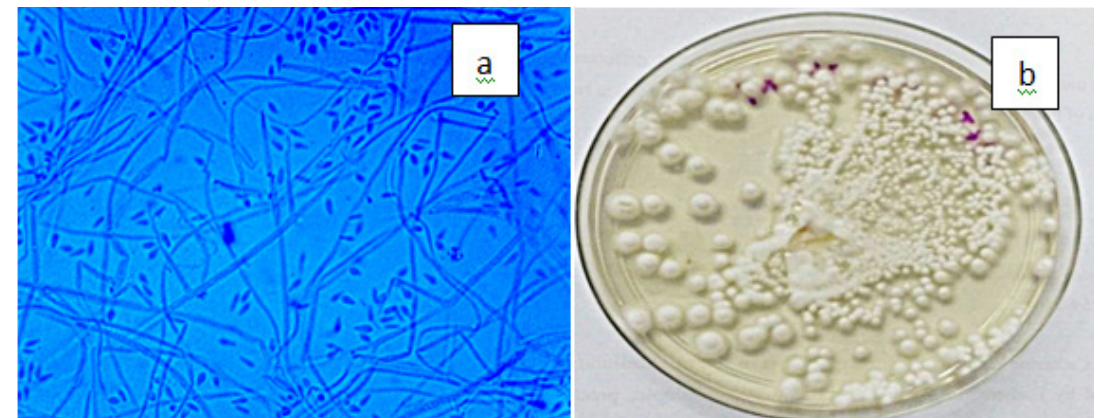

Figure 3(j) Sporothrix schenckii. a) Conidiferous denticles and blastoconidia of S. schenckii (xI00), b) White, glabrous and folded S. schenkii colony on PDA.

Citation: Mohd-Taib FS, Ahmad SN,Aqma WS, et al. Fungal communities in Macaca fascicularis and Macaca nemestrina associates with forest matrix types in West Malaysia.J Microbiol Exp. 2020;8(I):7-I8. DOI: 10.15406/jmen.2020.08.00279 

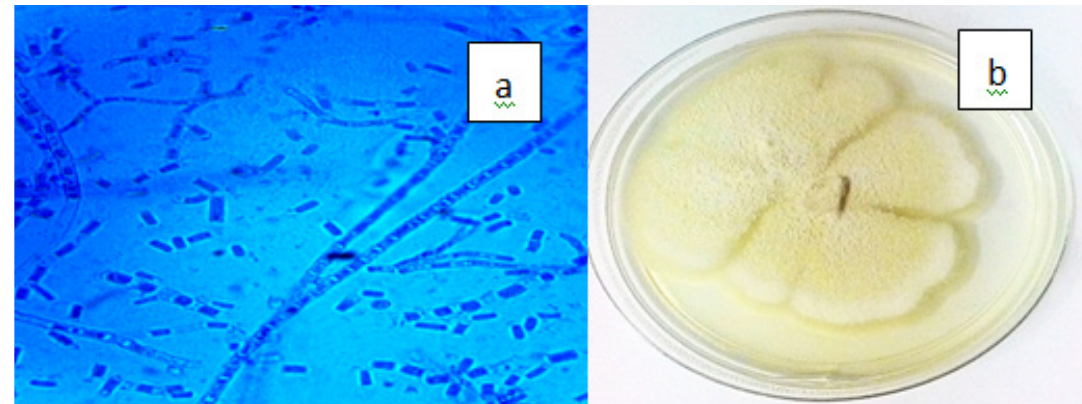

Figure 3(k) Geotrichum candidum. a) Dichotomous branching hyphae with conidial chains (x|00), b) White and butyrous colony on PDA.

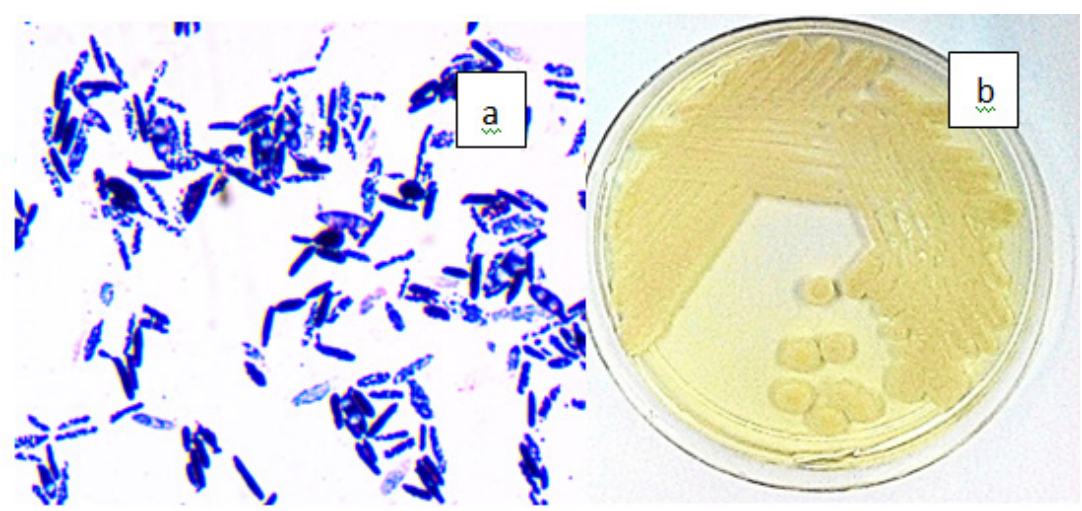

Figure 3(I) Candida parapsilosis. a) Globose to ovoid yeast cells (xI00), b) Cream and lacy colonies on PDA.
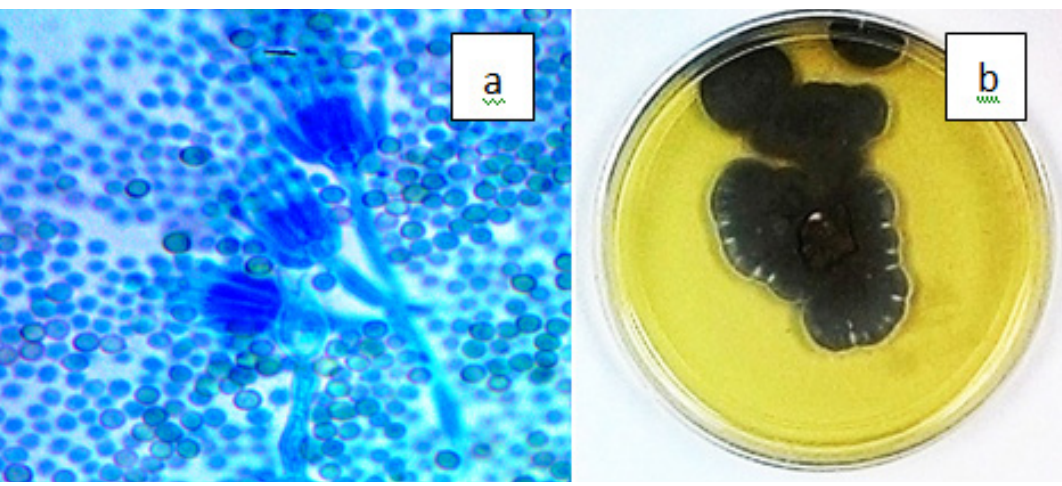

Figure 3(m) Penicillium jensenii. a) P. jensenii phialides and conidia (x|00), b) Folded, greyish green colony on PDA.
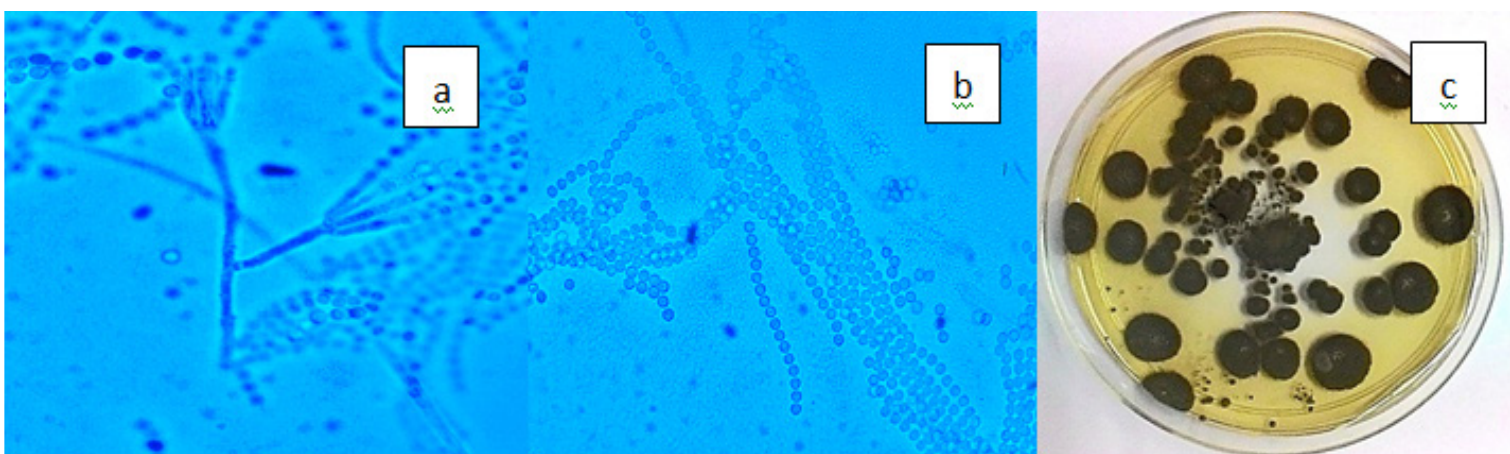

Figure 3(n) Penicillium frequentans. a) Conidiophores of P. frequentans (xI00), b) Conidia in long compact columns, c) Dark green and velvety colonies on PDA. 

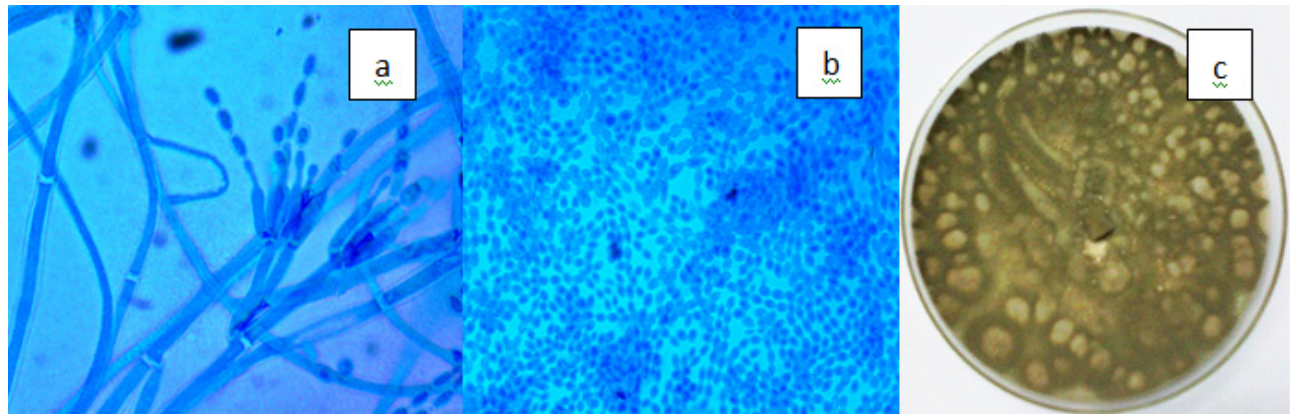

Figure 3(o) Penicillium canescen. a) Divergent metulae of P. canescens, b) Ovate, smooth-walled conidia ( $(100)$, c) Grey-green and powdery colonies on PDA.
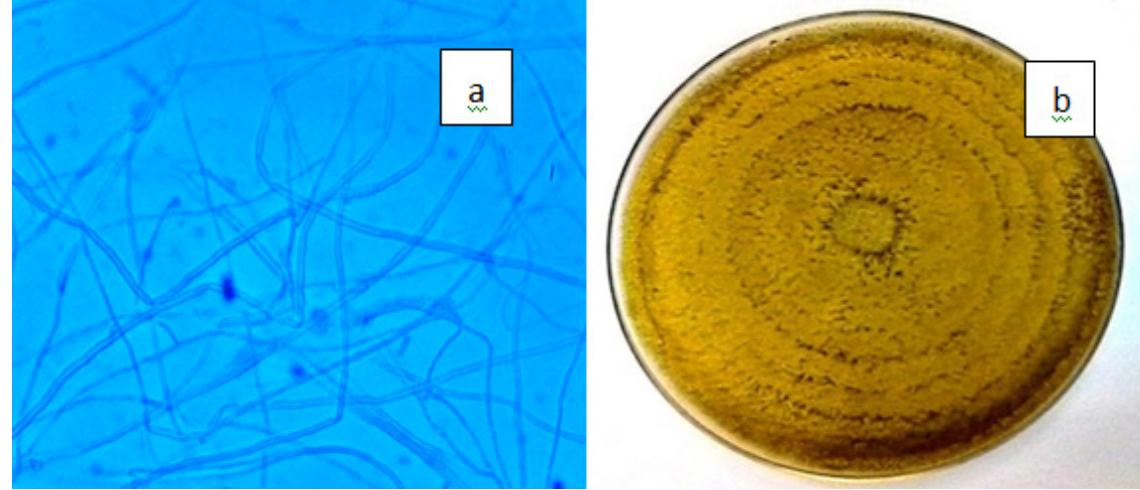

Figure 3(p) Phellinus sp., a) Hyaline, aseptate hyphae of Phellinus sp. (xI00), b) Brown, cottony colony with ring structure on PDA.
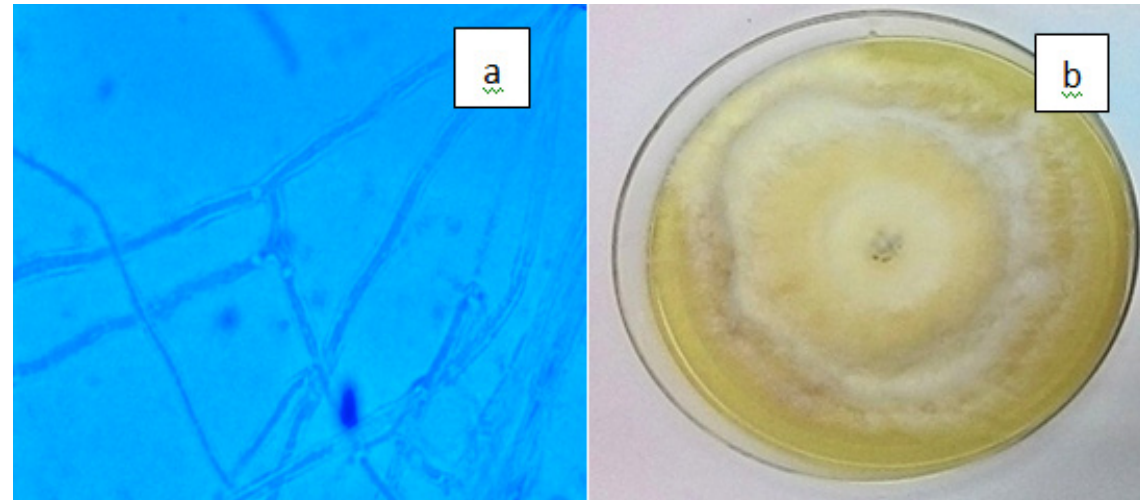

Figure 3(q) Basidiomycete sp., a) Hyaline, septate hyphae of Basidiomycete sp. (x100), b) White and cottony colony on PDA.
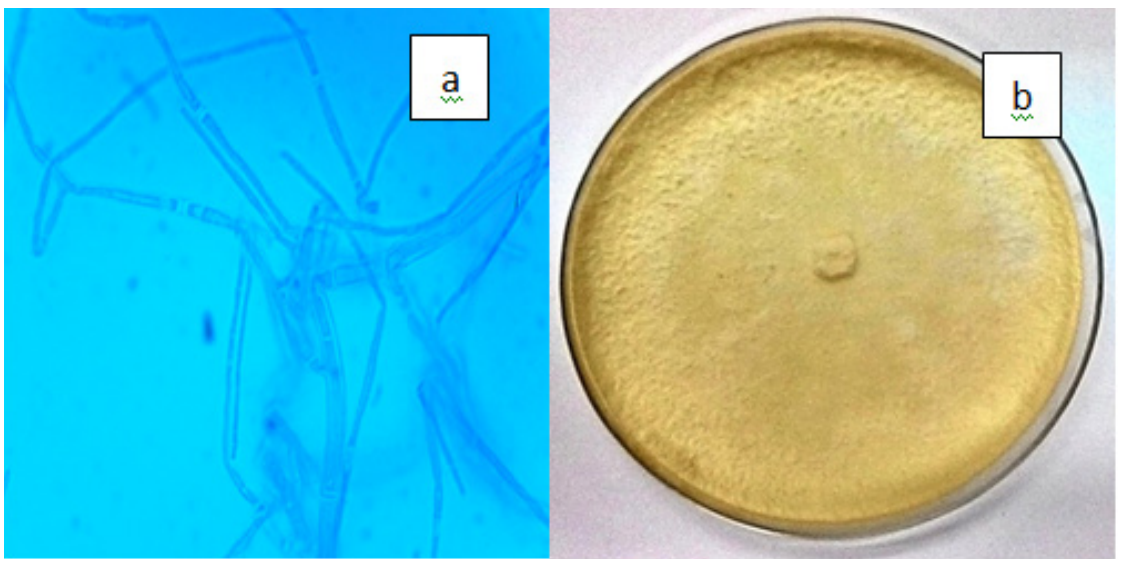

Figure 3(r) Phlebia sp., a) Hyaline, septate hyphae of Phlebia sp. (x 100), b) Orange-colored colony on PDA.

Citation: Mohd-Taib FS, Ahmad SN, Aqma WS, et al. Fungal communities in Macaca fascicularis and Macaca nemestrina associates with forest matrix types in West Malaysia.J Microbiol Exp. 2020;8(I):7-I8. DOI: I0.15406/jmen.2020.08.00279 


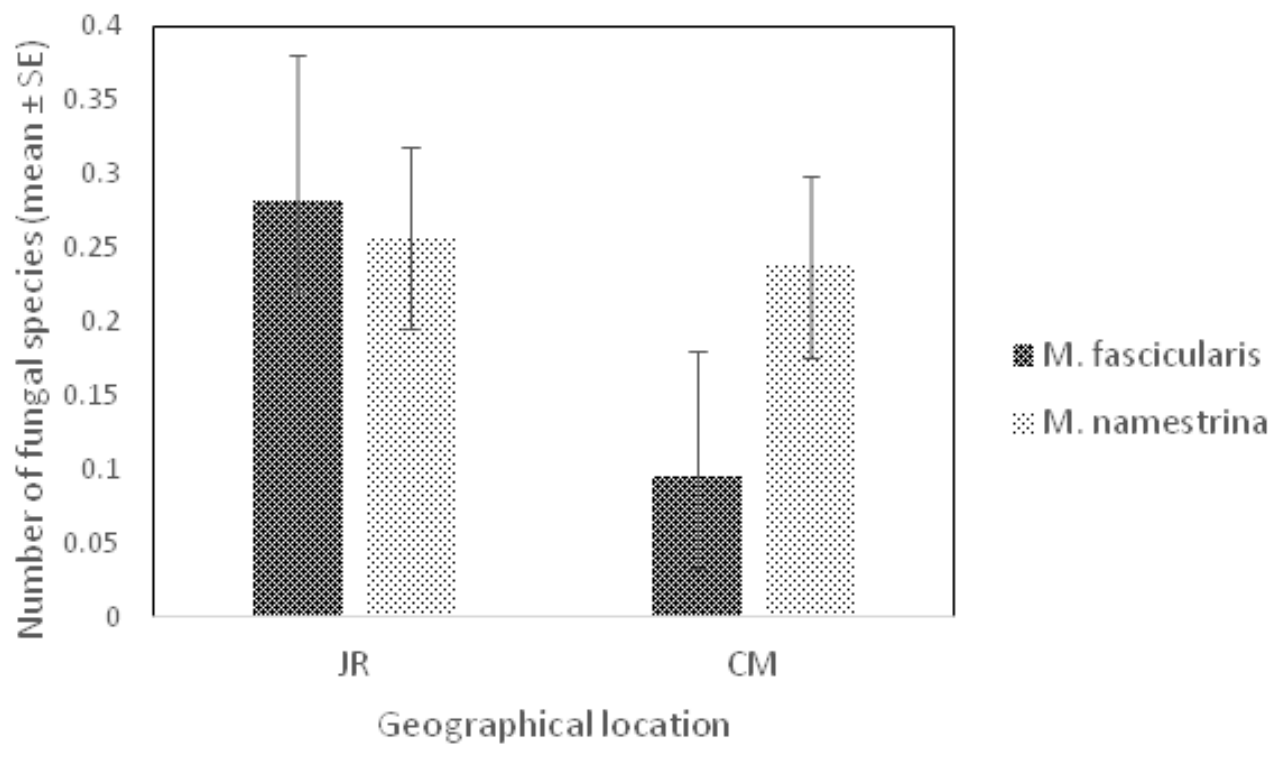

Figure 4 Distribution of fungal species in different macaques' species and geographical locations.

\section{Comparisons of fungal species distribution in different} anatomical sites

Figure 5(a \& b) illustrate distribution of fungal species according to anatomical and geographical locations for each individual macaques' species $(\mathrm{N}=12)$. Fungal species isolates from $M$. fascicularis was higher in JR with mean ranges from 2.7 to 3.7 species in all anatomical sites. M. fascicularis in CM only recorded $1.3 \pm 0.67$ fungi species in anus only. Similarly, fungal species isolated from M. nemestrina was higher in JR especially in throat with $3.7 \pm 0.3$, followed by penis/vagina and anus. M. nemestrina in $\mathrm{CM}$ on the other hand were isolated in anus and penis/vagina only. Similarly Kruskal-Wallis test revealed no significant difference between number of fungal species in different anatomical sites, $\chi^{2}(2)=1.832, p=0.4$. However, anus and penis/vagina site revealed higher fungi distribution compared to throat in M. fascicularis, whereas in M. nemestrina fungal species was higher in throat compared to anus and penis/vagina.

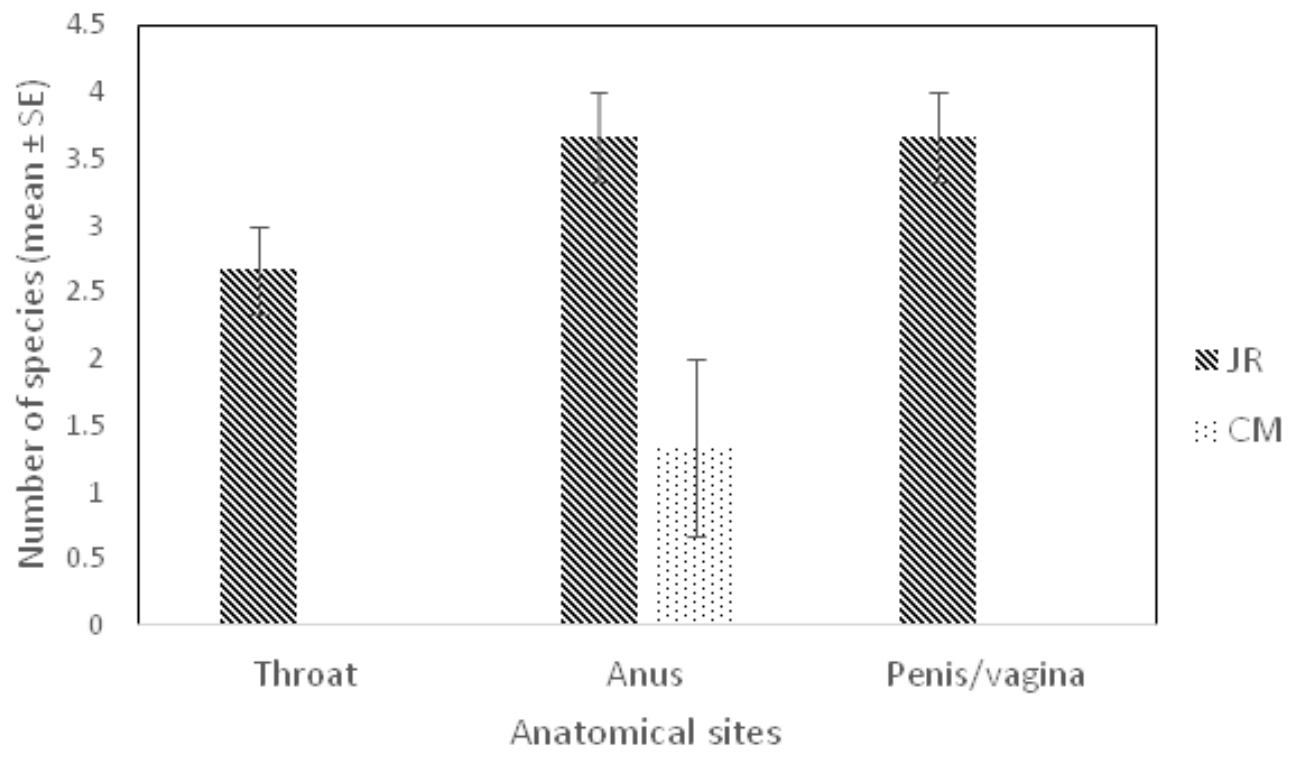

(a) 


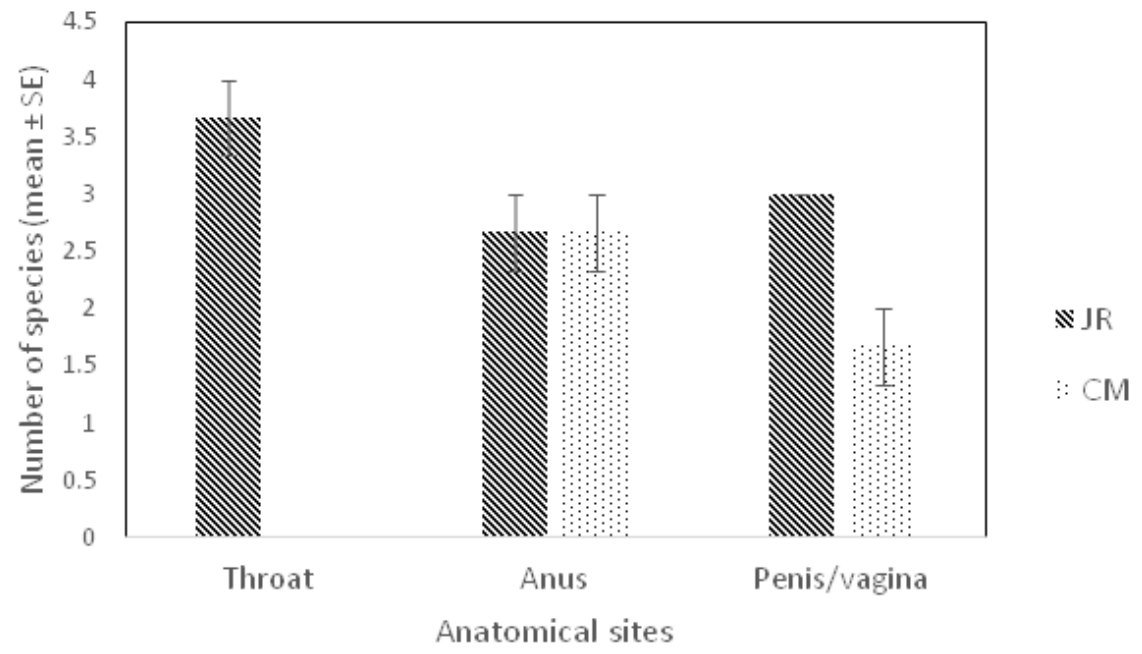

(b)

Figure 5 Comparison between numbers of fungal species isolated from Jambu Rias (JR) and Chemomoi (CM) in (a) M. fascicularis and (b) M. nemestrina.

In JR, 4 fungal species were isolated from anus and penis/vagina while 3 species were isolated from throat in $M$. fascicularis, whereby in M. namestrina, 3 species were isolated from anus and penis/vagina while 4 species were isolated from throat (Table 2). Compared to JR, throat in both macaques in $\mathrm{CM}$ did not show positive for any fungi species, as can be found in both anus and penis/vagina sites. Most of the isolated fungi were from the anus region of both $M$. fascicularis and $M$. namestrina. Only Aspergillus fumigatus fungi species was shared between both macaques species, in all anatomical sites in JR, but it was absent in samples from CM. However, Apergillus ruber and Aspergilus flavus were common isolates in both geographic locations.

\section{Discussion}

The study support our hypothesis as there were higher fungal distribution in macaques residing forest with oil palm plantation, compared to Acacia plantation matrix, for both species. The difference between the numbers of fungal species isolated from the study areas could be explained by the difference in topological cover between the two study areas. Even though both forest matrix were deforested for monoculture plantation, most of the foregone forest in CM was substituted by Acacia plantation. Acacia mangium, has been widely used for forest restoration and rehabilitation in Malaysia due to its rapid growth, and high productivity apart from its robust and high adaptability. ${ }^{18-20}$ These trees are believed to serve as additional food sources for many wildlife, as well as providing shelter for them, hence the macaques would not have to encroach into human's habitat in order to find food. Silva et al., ${ }^{21}$ reveal high abundance of phytophagous insect in the plantation, which could attract more wildlife species, including macaques. On the other hand, in JR, macaques are forced to forage in nearby human settlements, where such act of finding food in human settlements will eventually expose them to rubbish and food leftovers, thus increasing the chances of fungus transmission. As opposed to the Acacia trees, oil palm plantation did not serve as an adequate food source for the macaque because it does not provide enough nutrients that the forest usually offers.
In addition to that, with a more disturbed habitat, the macaques have higher susceptibility towards fungal transmission and infections. The bahavior of raiding through food trash in human settlement increase their chances of encountering growing pathogenic fungi. According to USDA, ${ }^{22}$ many fungi can be found growing in food materials such as poultry and meat including those in genus Alternaria, Aspergillus, Geotrichum and many others. These fungi can later infect or transmit to the macaques through inhalation of the spores, or simply by skin contact and the spores can get stuck between their furs. Even though most of the times the fungi will not cause infections in the macaques, however they can act as vectors that can transmit the spores to humans. ${ }^{23}$ Being extremely tolerant, the spores can survive up to a very long time being on the macaques' body before being transmitted to a more suitable medium for their growth. Fungal species were higher in M. namestrina especially in CM. This can be explained by their difference in food choices as previous studies have shown that M. namestrina has been observed to include fungi as part of their dietary intakes. ${ }^{24}$

Overall, Aspergillus sp. shows the highest prevalence and being the most ubiquitous among other genus in both macaque species. Aspergillus sp. grows very well in decaying organic matter such as food trash as they feed off the carbon. A. clavatus was isolated from all three anatomical sites of $M$. fascicularis although the condition offered in each site was different. Rectal region usually have anaerobic condition, in contrast to penis/vagina and throat which have open access to aerobic condition. The $\mathrm{pH}$ of each site is also different. Temperature of throat and rectal region may lies in the same range as both are located inside the body cavity $\left(37^{\circ} \mathrm{C}\right)$ as opposed to penis/ vagina. This is because most of Aspergillus sp. such as A. clavatus are adaptive and very tolerant, allowing them to grow in different physical environment. A. fumigatus was isolated from all three anatomical sites of both M. fascicularis and M. namestrina. According to KwonChung and Sugui, ${ }^{25}$ there are four features that make A. fumigatus an ubiquitous pathogen: 1) ability to survive and grow in a wide range of environmental conditions, 2) effective spore dispersal in air, 3) 
physical characteristics that allow conidia to reach the distal airways, and 4) rapid adaptability to the host condition and environment.

Mycelian fungi were the most frequently isolated from all three anatomical sites, with only one species of yeast, Candida parapsilosis isolated from Penile/vaginal sample of M. nemestrina in JR. Candida $\mathrm{sp}$. has been frequently isolated from the penis/vagina region of primates because the condition of the region that favors its growth. Healthy nonhuman primates are known to be colonized with yeast on reproductive tracts. ${ }^{26}$ Previous study by Steele et al. ${ }^{26}$ also has found Candida sp. in vaginal region of pig-tailed macaque or M. nemestrina, consistent with the finding of this study. Both Penicillium sp. found were isolated from throat samples of the two macaque species. $P$. frequentans was isolated from throat of $M$. fascicularis while $P$. jensenii from the throat of $M$. nemestrina. This finding suggests that the throat physical condition is favoring the growth of fungus from genus Penicillium. The aerobic condition in throat site is crucial in ensuring the growth of Penicillium sp. as they thrive the most in oxygen-rich region. Carvalho et al., ${ }^{5}$ have also isolated Penicillium $\mathrm{sp}$. only from oral cavity and throat and none were found in anal cavity as this may be due to the limited concentration of oxygen.

The isolation of Paecilomyces lilacinus from the anus of $M$. fascicularis and P. variotii from the anal region of M. nemestrina in this study is opposing the finding of Carvalho et al., ${ }^{5}$ that isolated Paecilomyces sp. from nasal and oral cavity of primate. These two sites have different physical condition, especially in term of oxygen availability, suggesting that Paecilomyces sp. is facultative anaerobic. Paecilomyces sp. is frequently found in composting vegetation and food substrates ${ }^{27}$ and just like any other fungal species found living in rectum, they reside in the region through the gastrointestinal tract. The warm temperature inside rectum favors the growth of thermophilic Paecilomyces genera. ${ }^{28}$

Curvularia lunata is a facultative plant pathogen and can usually be found in tropical country. This fungal species can be ingested together with the fruit and leaf by the frugivorous long-tailed macaque. ${ }^{29}$ It was only isolated from the anal region as it is part of the gastrointestinal tract, and the spores might find the region suitable for their growth. Sporothrix schenckii found in the throat of M. nemestrina is a dimorphic fungus and can be found throughout the world in soil and decaying vegetation. This fungus might come in contact whenever the macaque was ingesting plant materials. The presence of any particular fungal species however does not indicate that the host is infected with them. According to Moraes et al., ${ }^{23}$ fungi are known to be occasionally present in primates without causing any disease. Even though the host might not get infected by the fungus, they can act as vectors to carry the fungus to a more vulnerable host such as immune compromised humans or other primates.

The geography and genetic proximity between human population and macaques are posing great risk in term of pathogenic fungal disease transmission in humans. This study is crucial in assessing the impact of wildlife encroachment such as macaques into human settlements. The study revealed forest disturbance is posing higher risk of fungal disease transmission. Fungi distributions were also different in different anatomical sites associated with different level of habitat disturbance. Furthermore, more fungal species were isolated from $M$. namestrina compared to $M$. fascicularis, due to their dietary consumption type differences. This study suggests that JR pose higher potential for fungal transmission between NHP's and human due to its higher density of fungal species, compared to CM.
Furthermore, human settlements near their natural habitat could put risks towards the NHPs due to poor management of trash and waste which subsequently encourage trash raiding among macaques. These consequently permit and increase the fungal transmission to NHP's. Further actions should be taken by the authority, for relocating human settlements adjacent to forests, as well as proper waste management system for the welfare of both macaques and human.

\section{Acknowledgments}

None.

\section{Conflicts of interest}

Authors declare that there is no conflict of interest.

\section{References}

1. Twigg I. A warning of the possible decline in long tailed-macaques (Macaca fascicularis) in Peninsular Malaysia due to a program of indiscriminate culling. Oxford, UK: Unpublished report, Primate Conservation, Oxford Brookes University; 2008.

2. Pedersen AB, Davies TJ. Cross-species pathogen transmission and disease emergence in primates. EcoHealth. 2009;6(4):496-508.

3. Pfennig DW. Effect of Predator $\square$ Prey Phylogenetic Similarity on the Fitness Consequences of Predation: A Trade $\square$ off between Nutrition and Disease? The American Naturalist. 2000;155(3):335-345.

4. Richardson M, Mittermeier RA, Rylands A, et al. Macaca nemestrina. The IUCN Red List of Threatened Species; 2008.

5. Carvalho VM, Vanstreels RET, Paula CD, et al. Nasal, oral and rectal microbiota of Black lion tamarins (Leontopithecus chrysopygus). Brazilian Journal of Microbiology. 2014;45(4):1531-1539.

6. Latgé JP. Aspergillus fumigatus and Aspergillosis. Clinical Microbiology Reviews; 1999.

7. Seyedmousavi S, Guillot J, Arné P, et al. Aspergillus and aspergilloses in wild and domestic animals: A global health concern with parallels to human disease. Medical Mycology. 2015;53(8):765-797.

8. Jones-Engel L, Engel GA, Schillaci MA, et al. Primate-to-human retroviral transmission in Asia. Emerging Infectious Diseases. 2005;11(7):1028-1035.

9. Rougeron V, Sam IC, Caron M, et al. Chikungunya, a paradigm of neglected tropical disease that emerged to be a new health global risk. Journal of Clinical Virology. 2015;64:144-152.

10. Sam IC, Chua CL, Rovie-Ryan JJ, et al. Chikungunya virus in macaques, Malaysia. Emerging Infectious Diseases. 2015;21(9):1683-1685.

11. Nakgoi K, Nitatpattana N, Wajjwalku W, et al. Dengue, Japanese encephalitis and Chikungunya virus antibody prevalence among captive monkey (Macaca nemestrina) colonies of Northern Thailand. American Journal of Primatology. 2014;76(1):97-102.

12. Demanche C, Berthelemy M, Petit T, et al. Phylogeny of Pneumocystis carinii from 18 primate species confirms host specificity and suggests coevolution. Journal of Clinical Microbiology. 2001;39(6):2126-2133.

13. Mense MG, Batey KL, Estep S, et al. Disseminated coccidioidomycosis in a cynomolgus monkey (Macaca fascicularis). Journal of Primatology. 2013;2:111.

14. Simmons J, Gibson S. Bacterial and Mycotic Diseases of Nonhuman Primates. In Nonhuman Primates in Biomedical Research; 2012. 105$172 \mathrm{p}$. 
15. Howard DH. Fungi Pathogenic for Humans and Animals (in three parts). Part A: Biology. Florida, USA: CRC Press; 2002.

16. St-Germain G, Summerbell R. Identifying Filamentous Fungi: A Clinical Laboratory Handbook. 2nd ed. Belmont, CA: Star Publishing; 2011.

17. Raja HA, Miller AN, Pearce CJ, et al. Fungal Identification Using Molecular Tools: A Primer for the Natural Products Research Community. Journal of Natural Products; 2017.

18. Hashim MN, Mohd Hazim MA, Syafinie AM. Strategic forest plantation establishment in Malaysia for future product development and utilization. In Proceeding of Kuala Lumpur International Agriculture, Forestry and Plantation. Hotel Putra, Kuala Lumpur, Malaysia; 2015.

19. Krishnapillay DB, Mohamed AR, Appanah S. Forest RehabilitationThe Malaysian Experience. Keep Asia Green. 2007;1:85-123.

20. Tsai LM. Studies on Acacia mangium in Kemasul Forest, Malaysia. I. Biomass and productivity. Journal of Tropical Ecology. 1988;4(3):293302.

21. Silva FWS, Leite GLD, Guañabens REM, et al. Seasonal Abundance and Diversity of Arthropods on Acacia mangium (Fabales: Fabaceae) Trees as Windbreaks in the Cerrado. Florida Entomologist. 2015;98(1):170 174.

22. United States Department of Agriculture Food Safety and Inspection of Service. Food Safety Information. Molds on Food: Are They Dangerous?; 2013.
23. Moraes IA, Stussi JSP, Lilenbaum W, et al. Isolation and identification of fungi from vaginal flora in three species of captive Leontopithecus. American Journal of Primatology. 2004;64(3):337-343.

24. Lang C. Primate Factsheets: Pigtail macaque (Macaca namestrina). Taxonomy, Morphology \& Ecology; 2009.

25. Kwon-Chung KJ, Sugui JA. Aspergillus fumigatus-What Makes the Species a Ubiquitous Human Fungal Pathogen? PLoS Pathogens. 2013;9(12):1-4.

26. Steele C, Ratterree M, Fidel PL. Differential susceptibility of two species of macaques to experimental vaginal candidiasis. The Journal of Infectious Diseases. 1999;180(3):802-810.

27. Houbraken J, Varga J, Rico-Munoz E, et al. Sexual reproduction as the cause of heat resistance in the food spoilage fungus Byssochlamys spectabilis (anamorph Paecilomyces variotii). Applied and Environmental Microbiology. 2008;74(5):1613-1619.

28. Houbraken J, Verweij PE, Rijs AJMM, et al. Identification of Paecilomyces variotii in clinical samples and settings. Journal of Clinical Microbiology. 2010;48(8):2754-2761.

29. Bonadio C. Macaca fascicularis; 2000. 